\title{
Comparison of IgG antibody profiles by immunoblotting in patients with acute and previous Toxoplasma gondii infection
}

\author{
I L Moir, M M Davidson, D O Ho-Yen
}

\begin{abstract}
The IgG antibody profile to Toxoplasma gondii proteins of less than 37 kilodaltons in sera from patients with acute and previous infection was studied by immunoblotting. Bands at 28, 29, and 36 kilodaltons were more common in acute infection (10 out of 10 , nine out of 10 , and nine out of 10, respectively) compared with previous infection (five out of 10 , four out of 10 , and one out of 10 , respectively). The 6 kilodalton band was present in 10 out of 10 sera from patients with acute infection and five out of 10 sera from those with previous infection. A new observation is a doublet of bands of 22-25 kilodaltons present only in sera from patients with acute infection. This doublet may be a more reliable indicator of acute infection than the 6 kilodalton band.
\end{abstract}

Interpretation of serological data in toxoplasma infection can be complicated by the persistence of specific $\operatorname{IgM}$ and raised dye test titres in some patients for months or even years. ${ }^{12}$ Immunoblotting has been used to determine specific profiles of IgM and IgG reactivities in acute and previous infection. ${ }^{3-7}$ Information is available on the bands detected by the IgM response, ${ }^{3}$ but reports on the IgG response vary in detail. ${ }^{35}$ Controversy exists over the importance of low molecular weight antigens detected by IgG in the sera of patients with acute and previous infection. ${ }^{34}$ One recent study did not detect any bands of less than 25 kilodaltons, ${ }^{7}$ while others believe the 6 kilodalton band to be important in acute infection. ${ }^{34}$ The discrepancies may be explained by differences in antigen preparation, the separating gels, or the different patient groups studied. A high percentage of acrylamide in the separating gel gives better resolution of low molecular weight proteins. By using $15 \%$ polyacrylamide gels, we produced a detailed profile of IgG antibody reactivity in patients with acute and previous infection.

\section{Methods}

Sera were screened by in-house IgG and IgM enzyme linked immunosorbent assays $(\text { ELISA) })^{89}$ and further tested by the dye test. ${ }^{10}$ The results are given in International Units (IU). Specific IgM results were confirmed using a commercially available capture ELISA, Toxonostika IgM (Organon Teknika, The Netherlands). Three panels of sera were selec- ted from those being referred to the Scottish Toxoplasma Reference Laboratory, Raigmore Hospital, Inverness; (i) 10 from patients with acute symptomatic infection and within eight weeks of the start of the illness, dye test and IgM positive; (ii) 10 from patients with previous infection which had occurred more than 16 weeks earlier, dye test positive, and IgM negative; and (iii) 10 from patients with no serological evidence of current or previous infection, dye test and IgM negative. This group was selected from Paul Bunnell negative sera and all were within eight weeks of the start of the illness.

PREPARATION OF TOXOPLASMA ANTIGEN

Tachyzoites were harvested from the peritoneal cavities of cotton rats infected by intraperitoneal inoculation 66 hours previously with the RH strain of Toxoplasma gondii. After washing three times in phosphate-buffered saline (PBS) the pellet was resuspended in distilled water, frozen, and thawed three times and finally disrupted for three minutes in a sonic bath. An equal volume of $62.5 \mathrm{mM}$ TRIS- $\mathrm{HCl}$ sample buffer ( $\mathrm{pH} 6.9$ ) containing $2 \%$ sodium dodecyl sulphate (SDS) and $1 \%$ 2 -mercapto-ethanol was then added. The lysate was aliquoted into $100 \mu \mathrm{l}$ volumes and stored at $-20^{\circ} \mathrm{C}$.

SODIUM DODECYL POLYACRYLAMIDE GEL ELECTROPHORESIS (SDS-PAGE) AND ELECTROPHORETIC TRANSFER

The prepared antigen was boiled for three minutes and a tracking dye, $0.1 \%$ bromophenol blue in $50 \%$ sucrose, was added. It was then applied to $15 \%$ polyacrylamide slab gels, using a discontinuous sodium dodecyl buffer system. ${ }^{11}$ Gels were run at a constant current of $6 \mathrm{~mA}$ overnight. Molecular weight markers (glyceraldehyde 3-phosphate dehydrogenase, carbonic anhydrase, trypsinogen, trypsin inhibitor and lactalbumin) (Sigma Chemical Company Ltd) were used to construct a calibration curve. Proteins were transferred from the SDS slab gel to a nitrocellulose sheet at room temperature for four hours at a constant current of $300 \mathrm{~mA} .{ }^{12}$ The blotting buffer contained $20 \%$ methanol, $20 \mathrm{mM}$ TRIS, and $150 \mathrm{mM}$ glycine.

\section{IMMUNODETECTION}

After transfer the nitrocellulose sheet was soaked in PBS containing 5\% non-fat dried milk for one hour to block any remaining protein binding sites. Thereafter the nitrocellulose strips were incubated overnight at 
room temperature with a $1 / 100$ dilution of human serum in PBS $+0.05 \%$ Tween 20 (PBST) containing 5\% non-fat dried milk. The strips were washed five times in PBST then incubated for two hours at room temperature in a 1 in 500 dilution of goat anti-human IgG peroxidase conjugate (Sigma Chemical Company Ltd) in PBST $+5 \%$ non-fat dried milk. After five washes in PBST the strips were immersed in the substrate solution $(0.06 \% 4-$ chloro-1-naphthol in methanol, $0.014 \%$ hydrogen peroxide in PBS) for 10 minutes, washed twice in PBST, and dried. Continuous shaking was maintained throughout all incubation and washing steps.

\section{Results}

Serological data on the three panels of sera studied are shown in table 1 . Dye test titres ranged from 300-4000 IU in those with acute infection compared with 20-125 IU in those with previous infection. The normal range for our laboratory is $0-125$ IU. All 10 sera in the control group had dye test titres of $<8$ IU. Representative immunoblots of acute $(A, B)$ and previous $(C, D)$ infection and one immunoblot $(E)$ of a negative control are shown in the figure. IgG antibody to a range of antigens with molecular weights of less than 6-116 kilodaltons were identified in sera from patients with both acute and previous infection. The number and intensity of these bands varied, being more numerous and more strongly stained in sera from patients with acute infection. Only those bands of less than 37 kilodaltons were examined in detail. The antigens detected by IgG in the sera of the three groups are shown in table 2.

A diffuse broad band of about 6 kilodaltons was identified in 10 out of 10 and five out of 10 sera from patients with acute and previous infection, respectively. An additional but much fainter band could be detected below the 6

Table 1 Serological data on samples tested

\begin{tabular}{|c|c|c|c|}
\hline \multirow{2}{*}{$\begin{array}{l}\text { Patient } \\
\text { group }\end{array}$} & \multirow{2}{*}{$\begin{array}{l}\text { Case } \\
\text { No }\end{array}$} & \multicolumn{2}{|l|}{ Serological tests } \\
\hline & & Dye test (IU) & $\lg M$ \\
\hline Acute infection & $\begin{array}{r}1 \\
2 \\
3 \\
4 \\
5 \\
6 \\
7 \\
8 \\
9 \\
10\end{array}$ & $\begin{array}{r}500 \\
500 \\
300 \\
500 \\
650 \\
1000 \\
650 \\
1250 \\
2000 \\
4000\end{array}$ & $\begin{array}{l}+ \\
+ \\
+ \\
+ \\
+ \\
+ \\
+ \\
+ \\
+ \\
+\end{array}$ \\
\hline Previous infection & $\begin{array}{l}11 \\
12 \\
13 \\
14 \\
15 \\
16 \\
17 \\
18 \\
19 \\
20\end{array}$ & $\begin{array}{r}20 \\
65 \\
65 \\
125 \\
30 \\
30 \\
30 \\
65 \\
65 \\
30\end{array}$ & $\begin{array}{l}\bar{z} \\
\bar{z} \\
\bar{z} \\
\bar{z} \\
\overline{-} \\
\overline{-}\end{array}$ \\
\hline Controls & $\begin{array}{l}21 \\
22 \\
23 \\
24 \\
25 \\
26 \\
27 \\
28 \\
29 \\
30\end{array}$ & $\begin{array}{l}<8 \\
<8 \\
<8 \\
<8 \\
<8 \\
<8 \\
<8 \\
<8 \\
<8 \\
<8\end{array}$ & $\begin{array}{l}- \\
- \\
- \\
- \\
- \\
- \\
- \\
- \\
-\end{array}$ \\
\hline
\end{tabular}

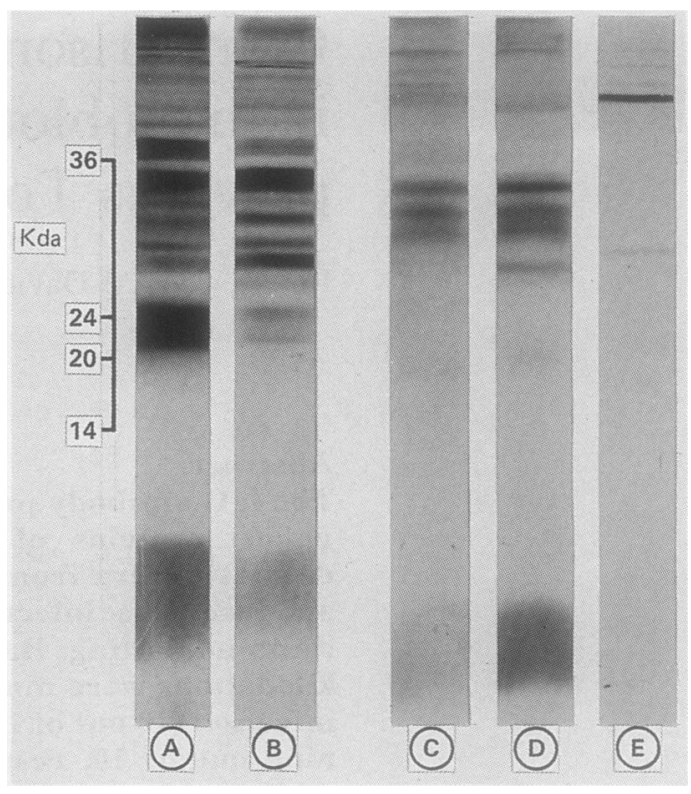

Immunoblot analysis of $T$ gondii antigens recognised by sera from patients with acute and previous infection and a seronegative control. Case numbers refer to those in tables 1 and 2 . Lane $A$, case 1; lane $B$, case 7 ; lane $C$, case 18 lane $D$, case 20 ; lane $E$, case 21 . Molecular weight markers are depicted on the left.

kilodalton antigen in three out of 10 sera from patients with acute infection. This band was absent in the sera of patients with previous infection. Neither band was seen in seronegative controls. A doublet of antigens with molecular weights of 22 and 25 kilodaltons was identified in nine out of 10 sera of patients with acute infection. Serum from case 3, taken four days after onset of symptoms, did not elicit a response to these bands. The profile from case 8 collected 14 days after onset showed a faint response to this doublet. Serum samples from the remaining eight patients were collected at least three weeks after onset. Bands of 28, 29, and 36 kilodaltons were more common in sera from patients with acute infection, whereas the $27,31,32$ and 34 kilodalton bands were present in both types of sera. In the control group five out of 10 sera identified faintly stained bands of 22, 28, 29, 32 and 34 kilodaltons. One serum reacted weakly with two antigens of 22 and 28 kilodaltons; the other four identified only one antigen. No bands were identified in the remaining five control sera.

\section{Discussion}

The ability of immunoblotting to provide a profile of specific antibody reactivity to individual antigens during the course of toxoplasma infection may provide a valuable addition to existing serological methods. The 6 kilodalton band has been proposed as an indicator of acute infection. ${ }^{34}$ An early study found this band in 24 out of 26 sera from patients with acute infection, but in only eight out of 22 of sera from those with previous infection. ${ }^{3}$ The 6 kilodalton band is the first to appear in the IgM response, in one case appearing before the IgM ELISA test became positive. ${ }^{6}$ It is also one of the earliest bands to be detected by the IgG response. ${ }^{56}$ The 6 
Table 2 Comparison of antigens identified by IgG in sera from patients with acute or previous infection

\begin{tabular}{|c|c|c|c|c|c|c|c|c|c|c|c|c|}
\hline \multirow{2}{*}{$\begin{array}{l}\text { Patient } \\
\text { group }\end{array}$} & \multirow{2}{*}{$\begin{array}{l}\text { Case } \\
\text { No }\end{array}$} & \multicolumn{11}{|c|}{ Antigens (kilodaltons) } \\
\hline & & $<6$ & 6 & 22 & 25 & 27 & 28 & 29 & 31 & 32 & 34 & 36 \\
\hline Acute infection & $\begin{array}{r}1 \\
2 \\
3 \\
4 \\
5 \\
6 \\
7 \\
8 \\
9 \\
10\end{array}$ & $\begin{array}{l}+ \\
+1- \\
- \\
- \\
+1- \\
= \\
= \\
=\end{array}$ & $\begin{array}{l}++ \\
+ \\
++ \\
+ \\
+++ \\
++ \\
+++ \\
+++ \\
+ \\
+++\end{array}$ & $\begin{array}{l}+++ \\
++ \\
- \\
++ \\
+++ \\
++ \\
++ \\
+ \\
++ \\
++\end{array}$ & $\begin{array}{l}+++ \\
++ \\
- \\
++ \\
+++ \\
++ \\
++ \\
+ \\
++ \\
++\end{array}$ & $\begin{array}{l}- \\
z \\
= \\
= \\
\overline{+} \\
+ \\
+ \\
+ \\
+\end{array}$ & $\begin{array}{l}++ \\
+++ \\
++ \\
+++ \\
+++ \\
+++ \\
+++ \\
+ \\
++ \\
++\end{array}$ & $\begin{array}{l}++ \\
++ \\
++ \\
++ \\
++ \\
++ \\
++ \\
+ \\
+\end{array}$ & $\begin{array}{l}++ \\
++ \\
++ \\
++ \\
++ \\
++ \\
+++ \\
++ \\
++ \\
+\end{array}$ & $\begin{array}{l}++ \\
++ \\
- \\
++ \\
++ \\
- \\
+++ \\
+ \\
-\end{array}$ & $\begin{array}{l}+++ \\
+++ \\
+++ \\
- \\
+++ \\
+++ \\
+++ \\
+++ \\
++ \\
++\end{array}$ & $\begin{array}{l}+++ \\
++ \\
+++ \\
- \\
+++ \\
++ \\
++ \\
+++ \\
++ \\
++\end{array}$ \\
\hline Previous infection & $\begin{array}{l}11 \\
12 \\
13 \\
14 \\
15 \\
16 \\
17 \\
18 \\
19 \\
20\end{array}$ & $\begin{array}{l}- \\
- \\
- \\
- \\
- \\
- \\
- \\
-\end{array}$ & $\begin{array}{l}+1- \\
- \\
- \\
+ \\
+1- \\
+ \\
+ \\
++\end{array}$ & $\begin{array}{l}- \\
- \\
- \\
- \\
- \\
- \\
- \\
- \\
- \\
-\end{array}$ & $\begin{array}{l}- \\
- \\
- \\
- \\
- \\
- \\
- \\
- \\
- \\
-\end{array}$ & $\begin{array}{l}- \\
- \\
- \\
- \\
- \\
- \\
- \\
-\end{array}$ & $\begin{array}{l}+ \\
+ \\
+ \\
- \\
- \\
- \\
+ \\
- \\
+\end{array}$ & $\begin{array}{l}+ \\
- \\
- \\
+ \\
- \\
+1- \\
+ \\
- \\
+ \\
-\end{array}$ & $\begin{array}{l}- \\
+ \\
+ \\
+ \\
+ \\
+1- \\
+ \\
++ \\
+ \\
++\end{array}$ & $\begin{array}{l}- \\
- \\
+ \\
+ \\
- \\
- \\
+ \\
++ \\
+ \\
++\end{array}$ & $\begin{array}{l}- \\
+ \\
++ \\
++ \\
+ \\
+ \\
++ \\
++ \\
+ \\
++\end{array}$ & $\begin{array}{l}- \\
- \\
- \\
- \\
- \\
- \\
- \\
+ \\
- \\
-\end{array}$ \\
\hline Controls & $\begin{array}{l}21 \\
22 \\
23 \\
24 \\
25 \\
26 \\
27 \\
28 \\
29 \\
30\end{array}$ & $\begin{array}{l}- \\
- \\
- \\
- \\
- \\
- \\
- \\
- \\
-\end{array}$ & $\begin{array}{l}- \\
- \\
- \\
- \\
- \\
- \\
- \\
- \\
-\end{array}$ & $\begin{array}{l}- \\
- \\
- \\
\overline{+} \\
- \\
- \\
- \\
- \\
-\end{array}$ & $\begin{array}{l}- \\
- \\
- \\
- \\
- \\
- \\
- \\
-\end{array}$ & $\begin{array}{l}- \\
- \\
- \\
- \\
- \\
- \\
- \\
- \\
-\end{array}$ & $\begin{array}{l}- \\
- \\
- \\
- \\
+1- \\
- \\
- \\
- \\
-\end{array}$ & $\begin{array}{l}+ \\
+1- \\
- \\
- \\
- \\
- \\
- \\
- \\
-\end{array}$ & $\begin{array}{l}- \\
- \\
- \\
- \\
- \\
- \\
- \\
- \\
-\end{array}$ & $\begin{array}{l}- \\
- \\
- \\
- \\
\overline{+} \\
\overline{-} \\
- \\
- \\
-\end{array}$ & $\begin{array}{l}- \\
- \\
- \\
- \\
- \\
- \\
+1- \\
- \\
- \\
-\end{array}$ & $\begin{array}{l}- \\
- \\
- \\
- \\
- \\
- \\
- \\
- \\
- \\
-\end{array}$ \\
\hline
\end{tabular}

Intensity of staining of bands: +++ very strong, ++ strong, + faint, $+/-$ very faint, - absent.

kilodalton protein is a surface glycoprotein and would be expected to give rise to an early antibody response, ${ }^{34}$ but it has also been detected in four out of five sera from patients with previous infection. ${ }^{6}$ Our results show that it was present in all sera from those with acute infection, but also more faintly in five out of 10 sera from those with previous infections and is therefore not a reliable indicator of early acute infection.

A band below 6 kilodaltons has only been reported once. ${ }^{6}$ It was measured at 4 kilodaltons in $10 \%$ gels. When eluted and reprocessed in $15 \%$ gels, two bands of 4.2 and $4 \cdot 4$ kilodaltons were detected. This 4 kilodalton band is generally thought to be equivalent to the 6 kilodalton band. ${ }^{3-5} \mathrm{We}$ detected a faint broad band of less than 6 kilodaltons in three out of 10 sera from patients with acute infection. This may be similar to the 4 kilodalton band or may represent a breakdown product of a higher molecular weight protein.

Bands representing "natural antibodies" have been found in all 44 sera taken from adults, but no one band was common to all. ${ }^{13} \mathrm{~A}$ study of sequential sera showed faint bands in pre-infection samples, some of which became more intense as infection developed. ${ }^{6}$ In our study faint bands were found in five sera from seronegative subjects, but none was consistently present in all sera.

The most striking feature of our results was the strong response to two antigens of 22 and 25 kilodaltons in nine out of 10 serum samples from patients with acute infection, but in none of the sera from those with previous infection. Serum from case 2 , in which these bands were absent, was taken four days after onset of symptoms; serum from case 8 , showing only faint bands, was taken two weeks after onset. In one previous report the 22 kilodalton band was not present until two and a half months later. ${ }^{14}$ This is consistent with a developing IgG response. Previous studies have reported a band corresponding to 22 kilodaltons in patients with either acute or previous infection, ${ }^{46}$ but the number of sera studied was small. The 22 kilodalton band was present in four out of five sera in one report ${ }^{6}$ and in a pool of six sera in another. ${ }^{4}$ There was no clinical information on the sera. A p22 protein has been recognised as a major surface antigen. ${ }^{1516} \mathrm{It}$ is not surprising, therefore, that a strong antibody response to this protein should be detected in acute sera. No other studies have referred to a 25 kilodalton band, but 24 and 26 kilodalton bands are mentioned, being present in both types of sera. ${ }^{317}$ In one report the 24 kilodalton band was more intense in sera from patients with acute infection. ${ }^{17}$ Because accurate measurement of molecular weights is difficult, our 25 kilodalton band may be the equivalent of one of these bands.

Bands of 28, 29, and 36 kilodaltons were more intensely stained in sera from patients with acute infection and more often found (10 out of 10 , nine out of 10 , nine out of 10 , respectively) than in those from patients with previous infection (five out of 10, four out of 10 , and one out of 10 , respectively). This corresponds to higher dye test titres in these sera. Antibody to antigens in the region of 27-29 kilodaltons are commonly found in both types of infection. ${ }^{367}$ There is no reported reference to a 36 kilodalton band, although bands of $38^{3}$ and $39-40$ kilodaltons ${ }^{9}$ have been detected. The relevance of the strong response to a 36 kilodalton protein in our study remains unclear. Bands of 31 and 34 kilodaltons present in almost all sera from patients with acute and previous infection may represent the p30 and p35 proteins, respectively. These are two major 
surface proteins of $T$ gondii tachyzoites ${ }^{1318}$ and a strong antibody response to them is common. ${ }^{36}$ Purified p 35 protein has been used as a diagnostic reagent ${ }^{19}$ and is a possible candidate vaccine in animals. ${ }^{14}$

The appearance of a strong IgG response to proteins of less than 25 kilodaltons disagrees with one recently published survey ${ }^{7}$ which did not regularly find these low molecular weight bands. This study used antigen grown in tissue culture, however, and there may be antigenic differences between tissue culture and peritoneal exudate tachyzoites. The tissue culture antigen was solubilised directly in SDS and mercaptoethanol to prevent protein breakdown; other preparations were made and stored in distilled water and solubilised immediately before electrophoresis. ${ }^{37}$ No 6 kilodalton band was detected when breakdown products were examined. ${ }^{7}$ We have shown distinct differences between the IgG immunoblots obtained from sera of patients with acute and previous toxoplasma infection. The presence of the 22-25 kilodalton doublet provides definitive information on the stage of $T$ gondii infection. Our clarification of previous reported results will allow the useful technique of immunoblotting to be used in diagnostic problems caused by toxoplasma infection.

We thank Miss Vivian MacFarquhar for typing the manuscript.

1 Fleck DG, Kwantes W. The laboratory diagnosis of toxoplasmosis. PHLS Monograph 13. London: PHLS, 1980.

2 Naot Y, Remington JS. An enzyme linked immunosorben assay for detection of IgM antibodies to Toxoplasma gondii: use for diagnosis of acute acquired Toxoplasmosis. J Infect Dis 1980;142:757-66. Erlich HA, Rodgers G, Vaillancours P, Araujo FG,
Remington JS. Identification of an antigen-specific
Immunoglobulin $M$ antibody associated with acute toxoplasma infection. Infect Immunol 1983;41:683-90.

4 Sharma SD, Mullenax J, Araujo FG, Erlich HA Remington JS. Western blot analysis of the antigens of Toxoplasma gondii recognized by human $\mathrm{IgM}$ and $\mathrm{IgG}$ antibodies. J Immunol 1983;131:977-83.

5 Partanen P, Thurunen HJ, Paasivuo RTA, Leinikki PO. Immunoblot analysis of Toxoplasma gondii antigens by human Immunoglobulins $\mathbf{G}, \mathbf{M}$ and $\mathbf{A}$ antibodies at different stages of infection. J Clin Microbiol 1984;20 133-5.

6 Potasman I, Araujo FG, Desmonts G, Remington JS. Analysis of Toxoplasma gondii antigens recognized by human sera obtained before and after acute infection. J Infect Dis 1986;154:650-7.

7 Verhofstede C, Van Gelder P, Rabaey M. The infectionstage-related IgG response to Toxoplasma gondii studied stage-related IgG response to Toxoplasma gondii stid
by immunoblotting. Parasitol Res 1988;74:516-20.

8 Joss AWL, Skinner LJ, Chatterton JMW, Chisholm SM, Williams H, Ho-Yen DO. Simultaneous serological screening for congenital cytomegalovirus and toxoplasma infection. Public Health 1988;102:407-17.

9 Joss AWL, Skinner LJ, Moir IL, Chatterton JMW, Williams $\mathrm{H}$, Ho-Yen DÓ. Biotin-labelled antigen screening test for toxoplasma IgM antibody. J Clin Pathol 1989;42:206-9.

10 Williams KAB, Scott JM, MacFarlane DE, Williamson JMW, Elias-Jones TF, Williams H. Congenital toxoplasmosis: a prospective survey in the West of Scotland. J Infect 1981;3:219-29.

11 Laemmlli UK. Cleavage of structural proteins during the assembly of the head of bacteriophage T4. Nature (Lond) 1970;227:680-5.

12 Towbin H, Staehelin T, Gordon J. Electrophoretic transfer of proteins from polyacrylamide gels to nitrocellulose heets: procedure and some applications. Proc Natl Acad Sci USA 1979;76:4530-54.

13 Potasman I, Araujo FG, Remington JS. Toxoplasma antigens recognized by naturally occurring human antibodies. J Clin Microbiol 1986;24:1050-4.

14 Araujo FG, Remington JS. Partially purified antigen preparations of Toxoplasma gondii protect against lethal infection in mice. Infect Immun 1984;45:122-6.

15 Couvreur G, Sadak A, Fortier B, Dubremetz JF. Surface antigens of Toxoplasma gondii. Parasitol 1988;97:1-10.

16 Kasper LH, Crabb JH, Pfefferkorn ER. Isolation and characterization of monoclonal antibody resistant mutant chacterization of monoclonal antibody resistant mutar

17 Suzuki Y, Thulliez P, Desmonts G, Remington JS. Antigen(s) responsible for immunoglobulin $G$ responses specific for the acute stage of toxoplasma infection in humans. J Clin Microbiol 1988;26:901-5.

18 Handman E, Goding JW, Remington JS. Detection and characterization of membrane antigens of Toxoplasma gondii. J Immunol 1980;124:2578-83.

19 Lindenschmidt EG. Demonstration of immunoglobulin M antibodies to Toxoplasma gondii antigenic component p35,000 by enzyme-linked antigen immunosorbent assay. J Clin Microbiol 1986;24:1045-9. 